\title{
4 \\ Application of Intelligent Networks in Banking
}

\author{
Troels Schmidt Jensen \\ Department of Telecommunication \\ Technical University of Denmark \\ DK-2800 Lyngby \\ Fax (+45) 45930355
}

\begin{abstract}
The actual application of telecommunications in banking is described from a service point of view. The future possibilities of using intelligent networks services is disscused. In particular we have dealt with the possibilities of the concept of Virtual Privat Network, VPN.
\end{abstract}

\section{Keywords}

Virtual private network, Intelligent networks in banking

\section{INTRODUCTION}

This paper is a discussion about the potential advantage for banks by the application of intelligent networks, $\mathrm{IN}$, in connection with communication. The discussion will primarily deal with the future use of an IN service, called Virtual Private Network, VPN.

\section{QUANTITATIVE USE OF TELECOMMUNICATION IN BANKING}

Today an intensive application of telecommunication is found especially within the financial sector. In the USA the transmission costs amount to approximately $40 \%$ of the total telecommunication costs in a typical financial institution. This may be converted into Danish conditions, which means that the total telecommunication costs amount to almost $10 \%$ of the operational costs of in banking. Therefore, the banks are very interested in teleservices, which can mean retrenchments of the costs of telecommunication.

The explosive development in the use of telecommunication is especially related to the growing use of datacommunication in connection with the introduction of technology for information and telecommunication within the financial sector. This development is reflected in the relative consumption of datacommunication of the sector compared to the consumption within other sectors. In 1989 the share of the financial sector in datacommunication costs for the telephone companies in Europe amounted to approximately $1 / 3$, far exceeding the relative size of the sector as well as the share of the sector in the total communication costs. The 
sectors share of the the total communication costs amounts to well over $10 \%$. These figures are an argument for the operators to take a special interest in the financial sector by the development and marketing of teleservices.

\section{THE GENERAL STRUCTURE OF IN}

A general construction of IN, containing advanced services - such as VPN - can be described shortly as follows (ref. figure): When a user makes a call to an IN service, the local exchange of the user transfers the call to an exchange with a Service Switching Function, SSF. This exchange is called a Service Switching Point, SSP. When the IN call has arrived in SSP (containing a trigger criterion with the function for deciding whether it is a call for a Public Switching Telephone Network, PSTN, or an IN service), a message is sent from SSP to Service Control Function, SCF. (SCF can possibly be in the same exchange and in such case the exchange is called a Service Switching Control Point, SSCP). If SCF and SPP are placed in different exchanges, the exchange, where SCF is placed, is called the Service Control Point, SCP. In SCF an analysis of the A-number and the B-number is performed by means of a database. Thus SSF forms the communication part between the user and IN, and SCF is in control of the dialogue.

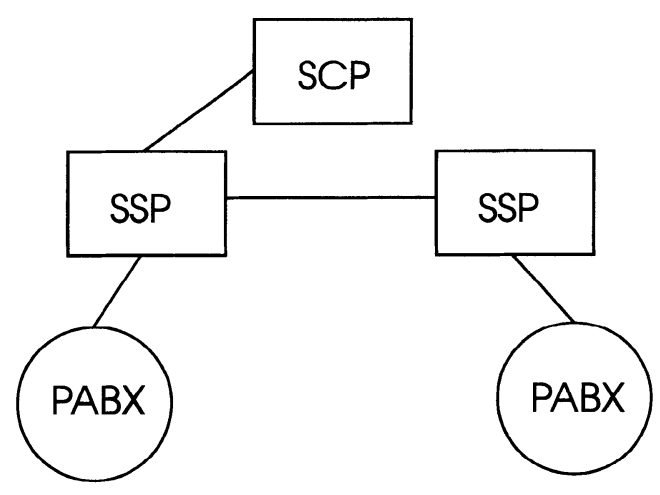

\section{CAPABILITY SET NO. 1}

The designation Intelligent Network was for the first time used by Bellcore in 1984. Since then the aim has been internationally to define an architecture of IN. This has resulted in some recommendations collected in one set called IN Capability Set no. 1, CS1. Two standardisation organisations have agreed upon CS1. These are ITU-T, The International Telecommunication Union, and ETSI, European Telecommunications Standards Institute. ITU's recommendations for IN are given by the Q.12xy-series. The number of CS has the 
index $\mathrm{x}$, and the description of its recommendation part has the index y. CS1 is described by the Q.121y-series, and full standardisation has not been performed until 1993.

With a basic view CS1 gives an open interface between the Service Control Point, SCP, and the Service Switching Point, SSP. This contributes in making IN services independent of the individual provider of telecommunication equipment. CS1 supports a number of IN services. Here 25 services are included out of which a couple are only supported partly by CS1. A great part of the CS1 services may advantageously be applied within the banking sector. In the client-related bank activities (front-office) especially the services: Credit Card Calling, CCC, and Freephone, FPH, will be relevant.

\section{IN AND CLIENT-RELATED BANK ACTIVITIES}

CCC gives the subscriber the possibility of calling from and to any place whatsoever. When the subscriber wishes to make a CCC call, the first action will be to press a PIN-code (Personal Identification Number). When calling, the bank account of the subscriber will automatically be charged the costs of the call.

Freephone is a service allowing subscribers to call e.g. a bank branch free of charge, where the bank will be debited with the costs of the call. It will be possible to combine this service with routing of calls by bank clients so that a bank has only one main number. When a client makes a call, this call will be routed to the nearest branch, irrespective of the place in the world from which the client makes the call. Or possibly by pressing a user number the call will be routed to the client's own branch. Furthermore, the service can be extended by an automatic telephone answering device to be applied in connection with calls not falling within the opening hours of the individual branches.

Finally, the functions of homebanking and officebanking are both applicable combined with one or both of the services mentioned above. Homebanking is a way of offering bank services through the Public Switching Telephone Network, PSTN (or PSDN), direct to the home of the client. This facility gives the client the possiblity of performing bank transfers and different forms of information services. Just as CCC, homebanking requires the IN service to be connected to the edp-exchanges of the individual banks. From a financial point of view the costs in connection with telecommunication, when using homebanking, can form the barrier for deliveries over long distances. Most private clients will hardly acceept to pay more than the local charge. However, this problem can be solved by the establishment of a node, passing on conversations, so that the client pays the local charge, and the bank pays any long-distance charge.

Officebanking is the answer of the corporate clients to homebanking, but with a wider functionality. The communication will often be channelised through dedicated data networks or leased lines. A great part of the small, middle-sized, and partly the big companies communicate through the public telephone network. The facilities offered to the corporate clients include access to financial information services, information about accounts, and other electronic payment services. Trade in securities can also be performed by an officebanking system. Actually most routine transactions can be arranged for the corporate clients. 
In the years to come all four IN services mentioned above will undoubtedly be far more in demand by bank clients in the part of the world which has an extended infrastructure for telecommunication. This means that the banks in the client-related operation will have an increased need of being able to offer such services, which again will mean an increased turnover for the operators.

\section{VIRTUAL PRIVATE NETWORK}

The sector-internal bank activity (back-office) means the activity performed internally in a bank company, for instance between the head office, subsidiary companies, branches, representative offices and agencies. By this facility a great deal of transmission of conversations and data in connection with e.g. trade in foreign exchange, trade in securities, clearing, booking, transactions, and credit information is made. Therefore, the CS1 service, VPN (Virtual Private Network), might possibly be applied with advantage in the internal banking operation. Besides, VPN's PABX (Private Automatic Branch eXchange) functionality may advantageously be applied for the construction of virtual dealing rooms. The PABX functionality may be relevant for both the client-related activity and the sector-internal activity.

Today the implementation of VPN services is solved by a switching-based VPN design. Here a relatively cheap starting VPN-service is offered which is quickly made more expensive by an increased number of switches. But by the development of IN, demanding large once-for-all investments, VPN operators can save costs as a centralisation of the information from the VPN configuration is possible. The use of software technology will furthermore mean an easier control of this information. Finally, there will be less likelihood of inconsistency between different nodes of the networks. Likewise it will be possible to extend the number of nodes without further investments.

In future the IN development will allow the VPN users - usually public network operators - to create client services which are independent of the sellers of VPN equipment. From the point of the public operators, VPN is a method of creating several private networks, using the common network infrastructure. This means that - with the same profit - the operators will be able to offer VPN services cheaper than fixed leased lines. Banks can remove some of or all their fixed leased lines to a VPN provider. Thus, the VPN service offers the banks to build virtual private networks by applying the resources of the public network. The lines of the subscribers = the bank departments, being connected to different switching nodes, hereby form a virtual Private Automatic Branch eXchange, PABX. This virtual PABX includes a private numbering plan, call transfer, call hold, routing information, all stored in a database at the VPN provider. Furthermore, the VPN-PABX may also include voice-response functions.

From any point whatsoever in the virtual private network it will be possible to obtain access to the network in accordance with authenticity. This authenticity gives the individual user access to a specific class of services providing specific rights and privileges. By change of places where private network facilities are desired or by changing capacity needs, it is easy for an operator to adjust by a software change the management configuration of the VPN services. (New design of modules named Service Independent building Block, SIB). 
The public network can offer private customers a complementary supplement to transmission, called Value Added Service, VAS. One of the most important VAS is centrex. Centrex provides full PABX functionality. Private companies, such as small bank branches, can quite quickly establish or abolish PABX-similar bank facilities even at small places. This is possible without big investments for a $\mathrm{PABX}$ system at the individual place. In the strict sense of the word, Centrex is a forerunner of the VPN services. It contains the PABX functions of the VPN service, but not the intelligent functions of it. Thus, Centrex does not form part of the VPN architecture, but it can still be an important service, allowing the users - even at small places - to obtain access to VPN services.

VPN can be used both as complete network or as part of a network for complying with specific wishes. When calling a VPN service, extra signalling is required as it must be possible for the exchange to distinguish between PSTN and VPN calls.

As a backbone for VPN it can be advantageous to apply the signalling system "Common Channel Signalling System No. 7, CCS\#7". CCS\#7 provides the VPN users PABX similar facilities in the public network. The signalling between two PABXs can either be end-to-end or link-by-link signalling. End-to-end signalling is limited by the fact that it is not easy to extend the VPN service for offering Centrex service or for overflow of the offered traffic into PSTN.

VPN is a supplement both to the existing private networks and to the fixed lines in the public network leased by a company with own its management. Both types of networks are, as mentioned above, applied by big banks in the sector-internal operation. Leased fixed lines are not always an ideal solution. For safety reasons their transmission capacity must be calculated as based on the peak traffic. (The traffic in busy hours). However, this means a low average occupation per line. Alternatively, the overflow of the peak traffic can be led to PSTN, but this will limit the transparency between the PABC users. By internal bank operation, all things considered, a certain minimum of offered traffic will be required, before leasing of a fixed line can be financially profitable. Besides leased lines are characterised by a fixed allocated bandwidth, only changeable with relatively big extra costs in case of a changed traffic pattern. From the companies' point of view, having a present or future need for a high and safe transmission capacity of data, telephony, and possibly video and graphic arts, the VPN advantages can be summarised as follows:

- Reduced management costs as more parts will share the management of the infrastructure.

- Reduced capital costs for purchase of communication equipment.

- Savings of telephone charges and costs in connection with leasing of fixed lines.

- Increased operating safety as VPN is used through the public network, PSTN.

\section{INTERNAL USE OF TELECOMMUNICATION IN BANKING}

Here follows a description of the strategies of the big banks for use of primarily internal networks. Since the end of the eighties when there have only been three alternative strategies for the banks, "Global", has been the keyword in the financial world.

1. Banks can build their own private systems and use them as competition tools. This strategy is only possible for the big banks.

2. Big banks can build systems (overcharge-network services), which can be sold to banks being too small for building their own systems. 
3. Banks can buy themselves into systems, established by others, or they can share systems based on public networks with other banks.

In principle, the existence of private financial service networks does not exclude the use of public switched networks. But in reality the banks operating on the international level have preferred to use privately leased fixed lines. Banks with bigger networks of these leased lines have built up centres, where management and supervision of the networks are being performed. Among others, this application of strategy number one is used by Citibank International Plc. Two main reasons for banks having developed such private networks during the seventies, the eighties, and partly the nineties, are the following:

- The increased data-service requirements from the banks were not generally available in the public networks. This includes problems with combining LAN's over public networks and often difficulties in setting the necessary services across national borders.

- The charge structure in the public network has made it advantageous for banks to lease fixed lines for high-capacity use.

These conditions gradually seem to be changed during the nineties. On the one hand, the new technology will reduce the costs for private networks and the European operators reduce the prices for leased fixed lines. But on the other hand, the public switched facilities will become more attractive for the financial institutions for two main reasons:

1. The net operators have started offering VPN, where lines are allocated dynamically in accordance with the needs of the clients. Besides the operator performs management and supervision of the virtually private network. This can mean a reliable and cost-effective solution for many big banks. VPN can advantageously be applied in connection with the third strategy of the banks.

2. Reason number 2 says that the banks have an increasing need for being connected directly to the clients.

\section{ADVANTAGES IN CONNECTION WITH USE OF VPN IN BANKING}

VPN will enable the banks to obtain access to advanced services, which today are not available from the established monopolists. In this connection John Sale, the leader of the group, European Virtual Private Network Users Association, has expressed: "Many of us are too eager to have audio conferences, telephone cards, common numbers and short codes".

A trade especially needing advanced telecommunication services, e.g. VPN services, are the banks. During recent years the banks have experienced big revolutions due to big trade slides, among other things in consequence of the strong development within the information and telecommunication technology. This gives the banks the possibility of entering into nontraditional bank areas such as credit secured by mortgage on real property, insurance and giro inpayment. But at the same time non-bank companies have entered into several bank services. Among other things, the insurance and finance companies have entered into banking, the retail trade offers its clients consumer loans, and telecompanies enter into various payment and credit systems. In the future it will be much easier to offer financial products by telephone, computer, or automatic teller machines. This means considerably less need for bank branches. 
Furthermore, using the telecommunication facilities the back-office functions might just as well be removed to relatively cheaper addresses outside the expensive finance centres.

It is quite difficult to give a survey of the VPN services' dynamic allocation af bandwidth for a virtual private network as against banks' leasing of fixed allocated bandwidths. This is due to the fact that the prices differ greatly when a bank department is to establish or extend a fixed leased line. The price i.a. depends on whether extra two- or four-wired lines have to lead to the department, on how far the department is situated from the nearest exchange, the conditions for the final destination of the line and on how great a capacity per time is desired for transfer. As to the prices of the VPN services, these of course for the same reasons, differ greatly, and depend on how advanced the desired intelligent PABX functionality must be. However, in any case it is an absolute must for the banks that at any time a VPN service guaranties the agreed transfer capacity and security against hacking. For small and middle-sized banks the savings of costs for management and supervision of private networks will speak in favour of the use of VPN services. But for the big banks, such as Citibank International plc., having already spent big sums af money on construction of networks and communication centres, the advantages will be limited. Furthermore, there are also some strategic reasons for big banks preferring their own communication networks.

VPN's PABX functionality can be used for construction of logical Dealing Rooms. In geographically differently placed bank departments a relatively small number of physical dealing positions (terminal places for dealers) can be established at any place. By means of the PABX function these can be connected to one logical Dealing Room. Small bank departments can quickly establish and abolish dealing positions as required. Besides, it is evident that the client dealers will be placed in one department, and the interbank dealers in another.

A modern dealing position is constructed as a multi-media terminal. From this conversation to and from clients, brokers, and other dealers shall be transferred. The other dealers can then be physically placed in the same department or in another geographically placed department. Besides conversation it shall be possible to send and receive text, graphic arts, and telex as well as to receive information from financial news services (text, graphic arts, audio, and video). To this must be added the access to data systems of the banks, e.g. daily update databases with risk management information. This means information about limits for amounts to be traded in with the individual client, and the rate of interest to be demanded by the customer. Furthermore, booking and tape recording (confirmation) of transactions are performed. All this means a strong and manysided utilisation of the different teleservices. A combination of more dealing departments into one big department on top of a common PABX functionality will therefore require a considerably higher transfer capacity. In connection with the morning meeting of the dealers it will i.a. be advantageous if video conferences could be arranged between these geographically separated dealing departments.

\section{CITIBANK INTERNATIONAL PLC.}

Citibank International plc. has branches for corporate clients in the capitals of Copenhagen, Stockholm, Oslo, and Helsinki. Each of these branches has approximately 30 employees. Through leased fixed lines they are interconnected mutually and as well as connected to the 
headquarters in London. It could be imagined that the four Nordic branches by means of VPN will be connected - either all functions or only the dealing functions - as one big virtual department. VPN's PABX functionality will then give this Nordic Citibank's department a number of common telephone numbers and a kind of common secretariat. Contrary to ordinary telephony VPN will furthermore ensure that the necessary bandwidth, as agreed in advance, will always be available.

As partly mentioned before Citibank International plc., using the mentioned communication Strategy 1, has already built up a private network, consisting of its own communication centres with tandem, management and supervision functionalities, its own private cables and leasing of fixed lines at public operators. To this must be added the establishment of ISDN2 and ISDN30 connections, today primarily applied as backup for the fixed leased lines. In the Northern countries it is e.g. furthermore possible to connect the modern MD110 PABX'es of the individual branches to one big virtual Northern PABX. Therefore, it is quite certain that, in years to come the bank will prefer to upgrade its own network instead of applying the VPN services.

\section{REFERENCES}

Ericsson, L.M. (1994) IN Survey. 1994. p. 1.5 - 1.13, 1.31

Martikainen, O., Lipiöinen. J. \& Molin, K. (1994) IFIP TC6 Workshop on Intelligent Networks. Lappeenranta University of Technology - Department of Information Technology. August 8-9 1994. pp. 53-55.

Schnepps, M. (1995) Intelligent Networks. Lecture Notes, Department of Telecommunication Technical University of Denmark. pp. 81-90.

United Nations. (1994) The Tradability of Banking Service - Impact and implications. Geneva. 148p.

Henten, A. (1995) Impacts of information and communication technologies on trade in services. Technical University of Denmark - Center for Tele Information. Januar 1995. 227 pp.

Falch, M., Henten, A. \& Skouby, K. E. (1993) DATE, Telematiserede bankydelser. Department of Social Sciences, Technical University of Denmark, pp. 57-60 (In Danish).

Jensen, T. S. (1995) Telekommunikation $i$ Banker. Department of Telecommunication, Technical University of Denmark. Master Thesis (in Danish).

\section{BIOGRAPHY}

Troels Schmidt Jensen got his M.Sc. in Telecommuncations in 1995. He has been working as a consultant in telecommucation and datacommuncation at Citibank $\mathrm{CPH}$. 